\title{
Business Efficiency Evaluation of Machine Tool Manufacturers by Data Envelopment Analysis (DEA): A Case Study of Taiwanese Listed Machine Tool Companies
}

\author{
Jui-Lung Chen ${ }^{1}$ \\ Department of Business Administration, National Chin-Yi University of Technology, Taiwan, R.O.C \\ Correspondence: Jui-Lung Chen, Department of Business Administration, National Chin-Yi University of \\ Technology, No.57, Sec. 2, Zhongshan Rd., Taiping Dist., Taichung 41170, Taiwan, R.O.C.
}

Received: October 14, 2021

Accepted: November 3, 2021

Online Published: November 17, 2021

doi:10.5539/ibr.v14n12p125

URL: https://doi.org/10.5539/ibr.v14n12p125

\begin{abstract}
Data envelopment analysis (DEA) is widely used to measure the business efficiency of many industries, among which the Taiwanese machine tool industry is well-known for its complete supply-chain system. Relying on DEA and Malmquist Productivity Index to analyze the business efficiency of Taiwanese listed machine tool manufacturers from 2018 to 2019, this study compared the changes in their business efficiencies and productivities. According to the five change indicators of Malmquist, only the technical efficiency, pure technical efficiency, and scale efficiency of the overall industry posted some growth during the research period, showing that the whole industry is actively improving its technical efficiency and striving to achieve the scale efficiency. However, technical change and total factor productivity declined slightly, indicating that the industry still makes more technical progress. Thus, companies should adjust their inputs and outputs to improve the production boundary for technical progress. The purposes of this study are to identify the success factors of the excellent performance of manufacturers and the benchmarking indicators of the decision-making unit on the efficient frontier results to provide some references for formulating future business strategies and direction.
\end{abstract}

Keywords: data envelopment analysis (DEA), Malmquist productivity index, business efficiency

\section{Introduction}

As a fundamental industry for the country, machinery is necessary for every modern industrial sector and engineering field. Machine tools, also called "Working Mother Machine," as the source of all industrial manufacturing, include a variety of processing machines in producing mechanical equipment and its components (e.g., lathes, milling machines, planers, and grinders). According to ISO standards, machine tools are mechanical devices driven by non-human power, typically used to process workpieces by selective removal or addition of physical, chemical, or mechanical components. As machine tools are fundamental for precise processing and manufacturing, this industry plays a key role in the overall economic system (Cheng and Chyou, 2012). In addition, the machine tool industry encompasses mechanical designing, processing, manufacturing, automated controlling, information software, electromechanical interface, system integration, and other related technologies. This sector represents the comprehensive industrial strength of a country. Being a highly technology-intensive and value-added industry, it plays an important supporting role in both the development of the manufacturing industry and the technical foundation of national industries. With a well-known international flexible production system, and a sound upstream and downstream operations in supply chains, Taiwan's machine tool industry can quickly deliver the supply and respond to customers' demands by its herd effect. Due to the Covid-19 pandemic, many countries have taken blockade measures one after another. The global economy has fallen into recession, the unemployment rate has risen, income has declined, and economic activities have shrunk significantly. Owing to the outbreak of Covid-19 and the long-standing US-China trade war, the output value of Taiwan's machine tools has decreased. However, as the Covid-19 was gradually taken under control in 2021, through stabilized screening and protective equipment, major breakthroughs in vaccine development, and financial and monetary stimulus measures of the government, the global economic activity began to slowly normalize. Therefore, the output value of machine tools posted a growing trend. According to the statistics of Taiwan Machine Tool and Accessory Builders' Association (2021), the output value of Taiwan machine tools in 2020 exceeded 3 billion US dollars, making Taiwan the fifth largest global exporter, thus proving machine tools as an important trade export 
product of Taiwan. Moreover, the number has fully reflected the level and quality of Taiwan's machine tools. Machine tool industry has supported Taiwan's industrial development by offering required production equipment for the domestic manufacturing industry (Chen and Tien, 2017; Chiu, 2016).

Lee (2017) pointed out that customer-oriented demands for Taiwan's machine tool industry have become increasingly diversified recently. The market orientation of products has gradually switched from mass production to small-volume and large-variety production. Low-tech, and low-precision processes were transformed into high-tech and high-precision ones. With the demand for customization greatly increased, this imposed a great challenge resulting from the change of production mode. Additionally, smart manufacturing and lean production management have become hot topics of the manufacturing industry now. If small and medium-sized enterprises fail to constantly adapt to the manufacturing environment and find their suitable production mode, they will soon be eliminated by the rapid development of the era which highlights accuracy and pragmatism (Ramadan and Salah, 2019). The machine tool industry tends to support manufacturing with a low-key and steady attitude which develops money-making products for other manufacturing industries. As machine tools usually have a longer life cycle compared with general consumer products, so they must maintain a high level of performance, quality, and reliability. Therefore, machine tool manufacturers must ensure reliable products to keep the maximum maintainability and productivity within the production line. Only highly reliable machine tools can give full play to their production capacities and create profits for customers (Pan, 2012).

To pursue sustainable development, the enterprise must pay attention to its performance with far-sighted visions. In fact, each organization aims to achieve the maximum profit or provide the best service with the minimum input. The operating performance evaluation of enterprises is to measure the performance results of enterprises within a certain period by specific methods and criteria in a particular index system, which can improve the decision-making and development of enterprises. Moreover, the indicators are the main elements of the performance evaluation management system, representing scales and dimensions of performance evaluation. Whether this goal can be achieved depends on the realization of sound organization, effective utilization of resources, and expected output. Therefore, all organizations attach great importance to performance without exception (Fortuin, 1988). In practice, except for revealing the utilization of production resources in an enterprise, performance evaluation also provides a reference for managers in planning future business strategies and making resource allocation decisions. Therefore, it becomes one of the most important topics for enterprise organizations. Business performance accounts for achieving organizational goals by improving the business performance is the goal of enterprise management decision-makers. In recent years, a wide range of areas related to production or efficiency, including finance, education and academic research institutions, medicine, transportation, and national defense, have employed Data Envelopment Analysis (DEA) to analyze. However, few researchers have adopted DEA to identify the operating efficiency of the tool machine industry. Based on the concept of Pareto Optimality used in economics, DEA measures the relative efficiencies of decision-making units (DMU) with multiple inputs and multiple outputs for the efficiency frontier. Additionally, the Malmquist productivity index is a mature and valuable research method for evaluating performance and efficiency. DEA can compute the relative efficiency of decision-making units by using multiple inputs and outputs at the same time, and can further provide suggestions for improving the business efficiency of decision-making units (Chandra, Cooper, Shanling, Rahman, and Cooper, 1998; Cooper, Seiford, and Tone, 2000). However, Malmquist Productivity Index can analyze DMU productivity changes and their causes during different periods combined with DEA's input. Hence, this study adopted both DEA and Malmquist Productivity Index to analyze the business efficiency of Taiwanese listed machine tool companies and compared the operating efficiency and productivity changes from 2018 to 2019. The purposes of the evaluation are to explore the success factors of manufacturers with good performance, and to benchmark the index of decision-making units on the efficient frontier results to provide some references for the following business strategies and direction.

\section{Preliminaries}

\subsection{CCR Model}

According to Mardani, Streimikiene, Balezentis, Saman, Nor, and Khoshnava (2018), the significant contributions of DEA include two aspects: First, based on actual inputs of DMU, DEA can generate production technologies that are uneasily observed in data without any rigid parameter hypothesis. Secondly, DEA can identify the inefficiency factor of relatively inefficient units. DEA can process both ratio-based data and non-ratio data simultaneously using different measurement units, making the data processing more flexible. DEA assumes the samples to be evaluated as a decision-making unit (DMU) (if there are $\mathrm{n}$ DMUs). Charnes, Cooper, and Rhodes (1978) proposed the CCR model. Following Farrell's notions of production efficiency evaluation, the model of double inputs and single output was changed into the efficiency measurement of multiple inputs 
and multiple outputs. Furthermore, under constant returns to scale (CRS), the production frontier was obtained by the linear programming method, and the relative efficiency of each decision-making unit was evaluated. The input-oriented model assumes that the $\mathrm{j}^{\text {th }} \mathrm{DMU}$ (for $j=1, \ldots, \mathrm{n}$ ) uses the $i^{\text {th }}$ (for $i=1, \ldots, \mathrm{m}$ ) input quantity as $X_{i j}$, and the $r^{\text {th }}$ (for $\mathrm{r}=1, \ldots, \mathrm{s}$ ) output as $Y_{r j}$, then the efficiency model of unit $k$ can be obtained using the following original model:

$$
\begin{aligned}
& \operatorname{Max} H_{k}=\frac{\sum_{r=1}^{s} u_{r} Y_{r k}}{\sum_{r=1}^{m} v_{i} X_{i k}} \\
& \text { s.t } \frac{\sum_{r=1}^{s} u_{r} Y_{r j}}{\sum_{r=1}^{m} v_{i} X_{i j}} \leq 1 \\
& u_{r}, v_{i} \geq \varepsilon>0, \quad r=1, \ldots, s, i=1, \ldots, m, j=1, \ldots, n \\
& \text { wherein } \\
& H_{k} \text { means the relative efficiency value } \\
& X_{i j} \text { means the } i^{\text {th }} \text { input value of the } j^{\text {th }} D M U \\
& Y_{r j} \text { means the } r^{\text {th }} \text { output value of the } j^{\text {th }} D M U \\
& u_{r} \text { means the weight of } i^{\text {th }} \text { input value } \\
& v_{i} \text { means the weight of } r^{\text {th }} \text { input value }
\end{aligned}
$$

Boyd and Färe (1984) found that, when either optimal solutions $u_{r}$ or $v_{i}$ is zero, the obtained solutions are degenerate in the CCR model. Although the efficiency is 1 , it's better to use the input. If $u_{r}$ or $v_{i}$ is zero, the efficiency value may be wrong. Therefore, non-Archimedean Quantity $\varepsilon$ is introduced as an arbitrarily small positive number to make $u_{r}$ or $v_{i}$ positive. According to Formula (1), under the condition of $H_{k} \leq 1$, when $H_{k}$ becomes closer to 1 , the production combination becomes more efficient; $H_{k}=1$ can obtain the most efficient rate. As Formula (1) is in fractional programming mode, it is not easy to reach a solution. After the conversion of parameters, Formula (1) is changed into linear programming as follows:

$$
\begin{gathered}
\operatorname{Max}_{k}=\sum_{r=1}^{s} u_{r} Y_{r k} \\
\text { s.t } \sum_{i=1}^{m} v_{i} X_{i k}=1 \\
\sum_{r=1}^{s} u_{r} Y_{r j}-\sum_{i=1}^{m} v_{i} X_{i j} \leq 0
\end{gathered}
$$




$$
u_{r}, v_{i} \geq \varepsilon>0, r=1, \ldots, s, i=1, \ldots, m, j=1, \ldots, n
$$

Based on Formula (3), when the weighted average combination value of input items is 1, the maximum weighted average combination value of output items can be obtained to indicate the relative efficiency value. However, the number of constraints $(n+s+m+1)$ is obviously more than the number of variables $(s+m)$, which can be converted into duality mode to reduce the number of constraints to find the solution easily. After the conversion, the dual problem can be divided into the following two types:

First Model:

$$
\begin{gathered}
\text { Min } H_{k}=\theta \\
s, t \sum_{j=1}^{n} \lambda_{j} X_{i j}-\theta X_{i k}=0 \\
\sum_{j=1}^{n} \lambda_{j} Y_{r j}=Y_{i k} \\
\lambda_{j} \geq 0, r=1, \ldots, s, i=1, \ldots, m, j=1, \ldots, n
\end{gathered}
$$

Wherein $\lambda_{j}$ represents non-negative scalar. According to Formula (6), the reference set of DMU is all the corresponding $\mathrm{j}$ while $\lambda_{j} \neq 0$. What's more, by adding the total weights of reference points $\sum_{j=1}^{n} \lambda_{j}$, we can determine the scale status of each DMU as follows:

$$
\begin{gathered}
\sum_{j=1}^{n} \lambda_{j}>1 \text { suggests decreasing returns to scale in the DMU } \\
\sum_{j=1}^{n} \lambda_{j}=1 \text { means constant returns to scale in the DMU } \\
\sum_{j=1}^{n} \lambda_{j}<1 \text { represents increasing returns to scale in the DMU }
\end{gathered}
$$

Second Model:

$$
\begin{gathered}
\operatorname{Min} H_{k}=\theta_{k}-\varepsilon \geq\left(\sum_{i=1}^{m} S_{i}^{-}+\sum_{r=1}^{s} S_{r}^{+}\right) \\
s, t \sum_{j=1}^{n} \lambda_{j} X_{i j}-\theta_{k} X_{i k}+S_{i}^{-}=0 \\
\sum_{j=1}^{n} \lambda_{j} Y_{r j}-S_{r}^{+}=Y_{r k} \\
\lambda_{j}, S_{i}^{-}, S_{r}^{+} \geq 0, r=1, \ldots, s, i=1, \ldots, m, j=1, \ldots, n
\end{gathered}
$$


Wherein the Formula (9), $\lambda_{j}, S_{i}^{-}, S_{r}^{+}$stands for the weight of each DMU combined with a linear equation under the optimal configuration as the actual efficiency value. Under constant returns to scale, DMC can still be improved for input or output items. Therefore, the slack variable of input/output items is introduced into the model as $S_{i}^{-}, S_{r}^{+}$respectively, which represents the difference between the actual and optimal efficiency, as well as how much room for improvement in input and output items. If $\theta=1, S_{i}^{-*}=S_{r}^{+*}=0$ it indicates the DMU is relatively efficient. When DMU is relatively inefficient, the slack variable analysis can reveal how much input should be reduced, and output should be increased to achieve efficiency. If $X_{i k}^{*}, Y_{r k}^{*}$ are the optimal input and output respectively in Formula (12) and Formula (13), $X_{i k}, Y_{r k}$ are actual values of input and output, then $S_{i}^{-*}, S_{r}^{+*}$ represent degrees of excessive input and insufficient output.

$$
\begin{aligned}
& \qquad X_{i k}^{*}=\theta X_{i k}-S_{i}^{-*} \\
& \qquad Y_{r k}^{*}=Y_{r k}+S_{r}^{+*} \\
& S_{r}^{+*} \text { means the slack variable of the } r^{\text {th }} \text { output variable } \\
& S_{r}^{+*} \text { means the slack variable of the } r^{\text {th }} \text { output variable } \\
& S_{i}^{-*} \text { means the slack variable of the } i^{\text {th }} \text { output variable } \\
& \text { Superscript } * \text { for the optimal value }
\end{aligned}
$$

\subsection{BCC Model}

Based on Banker, Charnes, and Cooper (1984), the proposed BCC model has modified the assumption of constant returns to scale in the CCR model, and variable returns to scale were put forward. The pure technical efficiency and scale efficiency can be deduced using four postulates of a production possibility set (curve property, no Pareto efficiency point, infinite relations, and minimum extrapolation) and the distance function of Shephard (1970). After taking variable returns to scale into consideration, we can adopt the following linear programming formula:

$$
\underset{\theta, \lambda}{\operatorname{Min}} H_{k}
$$

$$
\begin{gathered}
s, t \sum_{j=1}^{n} \lambda_{j} X_{i j} \leq H_{k} X_{i j} \\
\sum_{j=1}^{n} \lambda_{j} Y_{r j} \geq Y_{r k}
\end{gathered}
$$

$$
\sum_{j=1}^{n} \lambda_{j}=1
$$




$$
\lambda_{j} \geq 0, r=1, \ldots, s, i=1, \ldots, m, j=1, \ldots, n
$$

According to Formula (9), the efficiency value of constant return to scale (CRS) divided by Formula (14) equals the efficiency value of variable returns to scale, which is the scale efficiency. If the scale efficiency is 1 , it means that DMU reaches constant returns to scale; if the scale efficiency is less than 1, it means scale inefficiency. However, to understand whether the scale inefficiency is increasing or decreasing, it is necessary to introduce non-increasing returns to scale (NIRS) to compare with the scale efficiency under variable return to scale (VRS).

Moreover, as for the condition of non-increasing returns to scale, just change $\sum_{j=1}^{n} \lambda_{j}=1$ to $\sum_{j=1}^{n} \lambda_{j} \leq 1$ in Formula (17) as follows:

$$
\begin{gathered}
\operatorname{Min}_{\theta, \lambda} H_{k} \\
s, t \sum_{j=1}^{n} \lambda_{j} X_{i j} \leq H_{k} X_{i j} \\
\sum_{j=1}^{n} \lambda_{j} Y_{r j} \geq Y_{r k} \\
\sum_{j=1}^{n} \lambda_{j} \leq 1 \\
\lambda_{j} \geq 0, r=1, \ldots, s, i=1, \ldots, m, j=1, \ldots, n
\end{gathered}
$$

\subsection{Analysis of Malmquist Productivity Index}

One key point of enterprise management is to obtain the maximum output using the minimum input and output. As DEA can only compare each DMU within a single year rather than making a cross-sectional study in successive years, this study used the Malmquist Productivity Index (Malmquist, 1953) to measure the ratio of frontier changes in the utility possibility set. Unlike the static evaluation of DEA, the Malmquist Productivity Index is necessary for establishing the variable efficiency model to measure the dynamic intertemporal movement of operating efficiency.

On the basis of Färe, Grosskopf, Norris, and Zhang (1994), the Malmquist Productivity Index proposed by Caves, Christensen, and Diewert (1982) was applied in this study to measure the intertemporal movement of operating efficiency and to reveal whether the per-unit productivity has increased or decreased. To avoid errors caused by the selection of base period, we used the productivity index of in $t$ and $t+1$ periods to compute the geometric mean and measure changes in total factor productivity. Malmquist Productivity Index compares the changes of production possibility set during different periods, and the changes of production are divided into technical change (TECH-ch) and technical efficiency change (TE-ch) using the Shephard distance function. Distance function measures the ratio of input-output of DMU to the boundary distance, among which the efficiency change $\left(\mathrm{C}_{\mathrm{t}, t+1}\right)$ refers to the ratio of distance function in period $t+1$ to period $t$ under the condition of $C R S .\left(\mathrm{C}_{t, t+1}\right)$ can indicate the catch-up degree of relative efficiency and evaluate the efficiency improvement of DMU compared with the overall efficiency of Unit of Assessment (UOA). $\mathrm{C}_{t, t+1}>1$ suggests that the efficiency improvement of DMU is faster than that of UOA. $\mathrm{C}_{\mathrm{t}, t+1}=1$ means that the efficiency improvement of DMU is in pace with that of UOA. $\mathrm{C}_{\mathrm{t}, t+1}<1$ indicates that the efficiency improvement of DMU is slower than that of UOA.

The technical change $\left(S_{t, t+1}\right)$ means the relative distance of the production boundary in periods $t$ and $t+1$. When $\mathrm{S}_{\mathrm{t}, \mathrm{t}+1}>1$, the production boundary moves outwards, which means the technical progress of the whole industry. When $S_{t, t+1}<1$, the production boundary moves inwards to the origin, which means the technical recession of the whole industry. In addition, the Malmquist Productivity Index $\left(\mathrm{M}_{\mathrm{t}, t+1}\right)$ in $\mathrm{t}$ and $\mathrm{t}+1$ periods can be obtained by 
multiplying efficiency change and technical change. Additionally, under VRS, efficiency changes can be decomposed into pure technical efficiency change and scale efficiency change. Pure technical efficiency is the ratio of efficiency distance function in period $t+1$ to period $t$ under VRS, and efficiency change divided by pure technical efficiency change equals scale efficiency change.

$$
\begin{gathered}
C_{t, t+1}=\left[\frac{D^{t+1}\left(X_{t+1}, Y_{t+1}\right)}{D^{t}\left(X_{t}, Y_{t}\right)}\right] \\
S_{t, t+1}=\left[\frac{D^{t}\left(X_{t+1}, Y_{t+1}\right)}{D^{t+1}\left(X_{t+1}, Y_{t+1}\right)} \times \frac{D^{t}\left(X_{t}, Y_{t}\right)}{D^{t+1}\left(X_{t}, Y_{t}\right)}\right]^{1 / 2} \\
M_{t, t+1}=\left[\frac{D^{t}\left(X_{t+1}, Y_{t+1}\right)}{D^{t}\left(X_{t}, Y_{t}\right)} \times \frac{D^{t+1}\left(X_{t+1}, Y_{t+1}\right)}{D^{t+1}\left(X_{t}, Y_{t}\right)}\right]^{1 / 2}
\end{gathered}
$$

\section{Wherein}

$D^{t}\left(X_{t}, Y_{t}\right)$ means the output distance function of the $t^{\text {th }}$ period

$D^{t+1}\left(X_{t+1}, Y_{t+1}\right)$ means the output distance function of the $t+1^{\text {th }}$ period

$D^{t+1}\left(X_{t}, Y_{t}\right)$ means the output distance function of $\left(X_{t}, Y_{t}\right)$ in the period t based on the input and output of the $n^{\text {th }}$ DMC in the period $t+1$.

\section{Analysis of Empirical Results}

\subsection{Research Subjects and Variables Selection}

This study aimed at exploring operating efficiencies of Taiwanese listed machine tool companies. By the end of 2020, there were nine such companies in total. The sample period of this study was from 2018 to 2019, and the data of input and output variables originated from the Taiwan Stock Exchange Market Observation Post System and public financial statements of various companies. In this study, the cost method was mainly adopted to select input items, and expenditure items in the income statement were taken as resources for input variables. In addition, this selected four input items: operating cost, operating expense, total asset, and the number of employees, and two output items containing operating income and net operating profit after tax.

\subsection{Correlation Analysis of Input and Output Items}

The confirmed input and output items should be able to explain how each factor affects the efficiency. In other words, the input and output data must conform to the hypothesis of Isotonocity, which means that, when the input increases, the output should not decrease. Therefore, the correlation analysis between input and output items can help identify a positive or negative correlation. If there is a negative correlation, the variable should be eliminated. The analysis results are shown in Table 1. The correlation coefficient between input and output items was not negative, in line with the above hypothesis.

Table 1. Correlation Coefficients of Input and Output

\begin{tabular}{lll}
\hline \multicolumn{1}{c}{ Output } & Operating Revenue & Net Operating Profit After Tax \\
\hline Opput & $0.990^{* *}$ & $0.804^{* * *}$ \\
\hline Operating Cost & $0.980^{* *}$ & $0.846^{* *}$ \\
\hline Total Asset & $0.973^{* *}$ & $0.791^{* *}$ \\
\hline Number of Employees & $0.968^{* *}$ & $0.817^{* *}$ \\
\hline
\end{tabular}

$* *: p<0.01$ 


\subsection{Evaluation Results of DEA}

The DEA was applied to analyze the input and output data throughout 2019 , and the results are provided in the following table. After the application of DEA model, the relative efficiency of each unit was obtained as Table 2. In the chapters below, we would elaborate on the meaning of each empirical result.

Table 2. DEA Efficiency of Taiwanese Listed Machine Tool Manufacturers in 2019

\begin{tabular}{lllll}
\hline DMU & \multicolumn{1}{c}{$\begin{array}{l}\text { CCR } \\
\text { Efficiency } \\
\text { Value }\end{array}$} & $\begin{array}{l}\text { BCC } \\
\text { Technical } \\
\text { Efficiency }\end{array}$ & Scale \\
Efficiency \\
\hline $\begin{array}{l}\text { AWEA (AWEA MECHATRONIC CO., } \\
\text { LTD. ) }\end{array}$ & 0.9192 & 0.9408 & 0.9521 \\
\hline $\begin{array}{l}\text { CHEM (Chung-Hsin Electric and } \\
\text { Machinery Manufacturing Corp.) }\end{array}$ & 1 & 1 & 1 \\
\hline $\begin{array}{l}\text { FALCON (FALCON MACHINE } \\
\text { TOOLS CO., LTD. /Chevalier) }\end{array}$ & 0.9394 & 1 & 1 \\
\hline $\begin{array}{l}\text { GOODWAY (GOODWAY MACHINE } \\
\text { CORP.) }\end{array}$ & 0.9271 & 1 & 1 \\
\hline $\begin{array}{l}\text { HIWIN (HIWIN TECHNOLOGIES } \\
\text { CORP.) }\end{array}$ & 1 & 1 & 1 \\
\hline $\begin{array}{l}\text { Roundtop (Roundtop Machinery } \\
\text { Industries Co Ltd/ Johnford) }\end{array}$ & 1 & 1 & 1 \\
\hline KENTURN (KENTURN Co. Ltd.) & 0.8857 & 1 & 1 \\
\hline $\begin{array}{l}\text { Kinik } \\
\text { (Kinik Company) }\end{array}$ & 1 & 1 & 1 \\
\hline $\begin{array}{l}\text { TONGTAI (TONGTAI MACHINE and } \\
\text { TOOL CO., LTD.) }\end{array}$ & 1 & 1 & 1 \\
\hline
\end{tabular}

\subsubsection{CCR Model}

The Charnes, Cooper, and Rhodes (CCR) model calculated the overall technical efficiency for the unit, including management efficiency of operators and the company performance affected by its scale. The overall technical efficiency valuing "1" indicates a relatively high efficiency, representing an efficient DUM. The companies with an overall efficiency of 1 in 2019 are CHEM, HIWIN, Roundtop, Kinik, and TONGTAI. However, AWEA, FALCON, GOODWAY, and KENTURN are four companies that fail to achieve relatively high efficiency.

\subsubsection{BCC Model}

The Banker, Charnes, and Cooper (BCC) model was applied to assess the pure technical efficiency value, showing whether DMU can effectively use each input factor to maximize output. The larger the pure efficiency value is, the more efficient the DMU uses in each input factor. In terms of company operation, the overall technical efficiency refers to the management efficiency of company operators. The efficiency value of 1 represents that the company is relatively more efficient than other companies, and the efficiency value reaches the efficient frontier. Furthermore, it stands for relatively excellent management efficiency of companies. AWEA is the only company failing to achieve technical efficiency, which means that it made use of input resources inefficiently in 2019.

\subsubsection{Scale Efficiency}

Scale efficiency measures whether a company is being operated on the optimal scale. If its efficiency value is more than 1, DMU is increasing returns to scale (IRS), which requires expansion. If its efficiency value is less than 1, DMU is in the decreasing returns to scale (DRS), which requires the reduction. If the efficiency value equals 1, the input-output portfolio of DMU is in the optimal constant returns to scale (CRS). According to Table 2, except AWEA, management efficiencies of the other eight listed companies in Taiwan's machine tool industry entered the mature period.

\subsection{Analysis of Intertemporal Efficiency-Malmquist Productivity Index}

Referring to Table 3, for changes in management efficiencies of Taiwanese listed machine tool companies, only technology change and total factor productivity showed a declining trend. Even though, the decline was not so much, while other factors remained excellent. Hence, in summary, Taiwanese Listed Machine Tool Manufacturers continue to grow. 
Table 3. Changes in Business Efficiency of Taiwanese Listed Machine Tool Manufacturers from 2018 to 2019

\begin{tabular}{|l|l|l|l|l|l|}
\hline & $\begin{array}{l}\text { Change of } \\
\text { Technical } \\
\text { Efficiency }\end{array}$ & $\begin{array}{l}\text { Change of } \\
\text { Technologies }\end{array}$ & $\begin{array}{l}\text { Change of Pure } \\
\text { Technical } \\
\text { Efficiency }\end{array}$ & $\begin{array}{l}\text { Change of Scale } \\
\text { Efficiency }\end{array}$ & $\begin{array}{l}\text { Change of Total } \\
\text { Factor Productivity }\end{array}$ \\
\hline $2018-2019$ & 1.017 & 0.920 & 1.040 & 1.022 & 0.991 \\
\hline
\end{tabular}

\section{Results and Discussion}

The operating performance of enterprises is a combination of operational behaviors and operating results for enterprises. Generally, it measures the operating performance of enterprises within a certain period and evaluates whether the resources of enterprises have been efficiently employed. Hence, with this data, the operators of enterprises can check their performance, and more importantly, they can adjust and improve resource distribution. DEA has been widely used in many fields, which means that DEA is considered an effective method to evaluate organizational efficiency. To measure the level of performance objectively and reasonably, scholars and practitioners have developed many performance evaluation methods, among which DEA is an objective tool to deal with multiple input and output. Relying on the concept of relative comparison rather than the relationship between inputs and outputs, DEA measures the efficiency rating of each DMU and points out how each DMU should adjust the portfolio of inputs and outputs to improve efficiency. Based on the data of nine Taiwanese listed machine tool manufacturers from 2018 to 2019, this study used DEA to analyze technical efficiencies of companies and decomposed them into pure technical efficiency and scale efficiency to better evaluate the business efficiency of each company. In addition, we applied the Malmquist Productivity Index to evaluate the changes in the business efficiency of Taiwanese listed machine tool manufacturers. According to the five change indicators of Malmquist, only the technical efficiency, pure technical efficiency, and scale efficiency of the overall industry posted some growth during the research period, showing that the whole industry is actively improving its technical efficiency and striving to achieve the scale efficiency. However, technical change and total factor productivity declined slightly, indicating that the industry still makes more technical progress. Thus, companies should adjust their inputs and outputs to improve the production boundary for technical progress. Also, to meet future industry demands, Taiwan's machine tool industry should develop emerging technologies as soon as possible. In the past, Taiwanese manufacturers have achieved excellent performance in promoting automation, with the advantage of good production quality. In the future, they will head towards the long-term goal of Industry 4.0, which will bring in bigger opportunities. The growth of emerging markets and new technologies have contributed to the output value of the global machinery industry.

Moreover, as most of Taiwan's machine tool manufacturers are small and medium-sized except for listed ones, it is difficult for them to achieve the efficiency of economies of scale and enter the international market on their own. Therefore, the government should take the initiative to enhance the capital and technologies offered to manufacturers, respond to the demands of manufacturers more rapidly, and timely guide or coordinate among the cooperation between manufacturers. Then, by implementing relevant measures to assist domestic manufacturers in expanding foreign markets, relevant public departments or research institutions should proactively assist manufacturers in improving technology and product quality. Only in this way can Taiwan's machine tool products be successfully introduced to the overseas market.

According to Daft (2001), since the organization has multiple targets, the measurement of goal achievement level should cover objective and subjective indicators, measuring performance a complex problem. In the efficiency analysis, the study directly cited secondary data of relevant annual reports as input and output items and analyzed those objective data thoroughly. However, for some indicators of output items, if the primary data of subjective indicators can be collected using the survey, it can better reflect stakeholders' opinions. Moreover, although focusing on business efficiency, this study only touched on the efficiency analysis based on the limitations of secondary data and did not deeply explore exogenous variables affecting business efficiency. Hence, this study can be improved by follow-up research. In addition, to obtain the factor cost, the DEA method can be applied to evaluate the allocation efficiency in the following research. This study only compares the efficiencies between two years. In the future, researchers may employ DEA for multi-year efficiency evaluation to solve the problems of organizations and industries.

\section{References}

Banker, R. D., Charnes, A., \& Cooper, W. W. (1984). Some models for estimating technical and scale inefficiencies in data envelopment analysis. Management Science, 30(9), 1078-1092.

https://doi.org/10.1287/mnsc.30.9.1078 
Boyd, G. A., \& Färe, R. (1984). Measuring the efficiency of decision making units: A comment. European Journal of Operational Research, 15(3), 331-332. https://doi.org/10.1016/0377-2217(84)90101-2

Caves, D., Christensen, L., \& Diewert, W. E. (1982). The economic theory of index numbers and the measurement of input, output, and productivity. Econometrica, 50(6), 1393-1414. https://doi.org/10.2307/1913388

Chandra, P., Cooper, W. W., Shanling, L., \& Rahman, A. (1998). Using DEA to evaluate 29 Canadian textile companies: Considering returns to scale. International Journal of Production Economics, 54(2), 129-141. https://doi.org/10.1016/S0925-5273(97)00135-7

Charnes, A., Cooper, W. W., \& Rhodes, E. (1978). Measuring the efficiency of decision making units. European Journal of Operational Research, 2(6), 429-444. https://doi.org/10.1016/0377-2217(78)90138-8

Chen, L., \& Tien, M. (2017). External shocks, and the construction and functioning mechanisms of regional economic resilience. City and Planning, 44(1), 1-25. https://doi.org/10.6128/CP.44.1.1

Cheng, Y., \& Chyou, J. (2012). Toward machine tool industry-specific ERPs: A study on the characteristics and unique ERP functional requirements of the machine tool industry. Journal of Management and Systems, 19(2), 311-332. https://doi.org/10.29416/JMS

Chiu, W. (2016). Global Industry 4.0 trends of machine tool industry in Taiwan. Taiwan Economic Research Monthly, 39(3), 107-112. https://doi.org/10.29656/TERM.201603.0016

Cooper, W., Seiford, L., \& Tone, K. (2000). Data envelopment analysis: A comprehensive text with models, applications, references. Boston, MA: Kluwer Academic Publishers.

Daft, R. A. (2001). Organization theory and design (7th ed.). Ohio: South-Western College Publishin.

Färe, R., Grosskopf, S., Norris, M., \& Zhang, Z. (1994). Productivity growth, technical progress, and efficiency change in industrialized countries. The American Economic Review, 84(1), 66-83. Retrieved from https://www.jstor.org/stable/2117971

Fortuin, L. (1988). Performance indicators: Why, where and how? European Journal of Operational Research, 34(1), 1-9. https://doi.org/10.1016/0377-2217(88)90449-3

Lee, C. (2017). The application of lean production way into various and small amount production enterprises. Journal of Global Business Openration and Management, 9, 143-160. https://doi.org/10.29967/JGBOM

Malmquist, S. (1953). Index numbers and indifference surfaces. Trabajos de estadística, 4, 209-242. https://doi.org/10.1007/BF03006863

Mardani, A., Streimikiene, D., Balezentis, T., Saman, M., Nor, K., \& Khoshnava, S. (2018). Data envelopment analysis in energy and environmental economics: An overview of the state-of-the-art and recent development trends. Energies, 11(8). https://doi.org/ 10.3390/en11082002

Pan, Y. (2012). Foresee the development of machine tool industry from the product reliability viewpoint. Quality Magazine, 48(10), 9-12. https://doi.org/10.29999/QM.201210.0003

Ramadan, M., \& Salah, B. (2019). Smart lean manufacturing in the context of Industry 4.0: A case study. International Journal of Industrial and Manufacturing Engineering, 13(3), 174-181. https://doi.org/10.5281/zenodo.2643523

Shepard, R. W. (1970). Theory of Cost and Production Function. Princeton: Princeton University Press.

Taiwan Machine Tool and Accessory Builders' Association (2021). Retrieved from https://www.tmba.org.tw/

\section{Copyrights}

Copyright for this article is retained by the author(s), with first publication rights granted to the journal.

This is an open-access article distributed under the terms and conditions of the Creative Commons Attribution license (http://creativecommons.org/licenses/by/4.0/). 